Supplement of Hydrol. Earth Syst. Sci. Discuss., 11, 10683-10724, 2014

http://www.hydrol-earth-syst-sci-discuss.net/11/10683/2014/

doi:10.5194/hessd-11-10683-2014-supplement

(C) Author(s) 2014. CC Attribution 3.0 License.

(c) (1)

Supplement of

\title{
How does bias correction of RCM precipitation affect modelled runoff?
}

\section{J. Teng et al.}

Correspondence to: J. Teng (jin.teng@csiro.au) 
Supplementary Table: Kolmogorov-Smirnov test results for fitting gamma and double gamma distribution on observed and RCM precipitation.

$D$ is the maximum vertical distance between the empirical and fitted theoretical CDFs (the smaller the better), and the $p$-value is the statistical

significance (the larger the better). A p-value greater than 0.05 is generally considered a good fit and thus highlighted with shading.

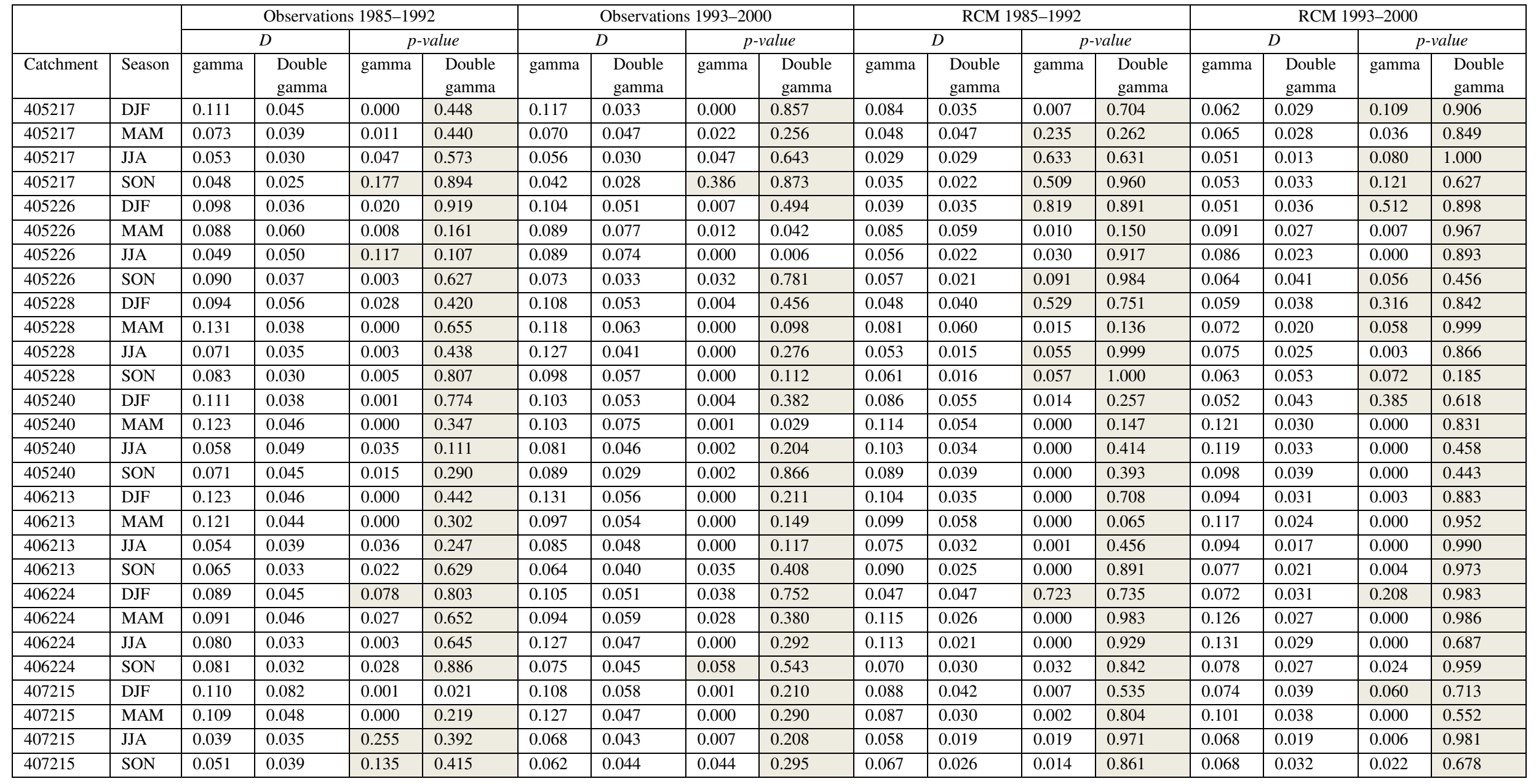




\begin{tabular}{|c|c|c|c|c|c|c|c|c|c|c|c|c|c|c|c|c|c|}
\hline 407222 & DJF & 0.113 & 0.042 & 0.000 & 0.573 & 0.111 & 0.052 & 0.000 & 0.324 & 0.107 & 0.058 & 0.000 & 0.106 & 0.101 & 0.044 & 0.001 & 0.430 \\
\hline 407222 & MAM & 0.074 & 0.056 & 0.010 & 0.098 & 0.087 & 0.063 & 0.002 & 0.048 & 0.100 & 0.034 & 0.000 & 0.598 & 0.118 & 0.037 & 0.000 & 0.494 \\
\hline 407222 & JJA & 0.037 & 0.021 & 0.305 & 0.922 & 0.064 & 0.032 & 0.010 & 0.539 & 0.052 & 0.016 & 0.048 & 0.993 & 0.082 & 0.015 & 0.000 & 0.999 \\
\hline 407222 & SON & 0.044 & 0.048 & 0.246 & 0.181 & 0.060 & 0.042 & 0.059 & 0.341 & 0.080 & 0.024 & 0.001 & 0.878 & 0.073 & 0.025 & 0.005 & 0.868 \\
\hline
\end{tabular}

